\title{
2
}

\section{The Institutional Change Agency: The Expanding Role of Academic Support Centers}

\section{Robert M. Diamond}

President, National Academy for Academic Leadership

Higher education is going through significant changes stimulated by the rapid growth of the internet, the increasing globalization of higher education, and the ever-pressing question of institutional quality. New modes of educational delivery through virtual networks are breaking the traditional mold of instructional provision. New players, new pedagogies, and new paradigms are redefining higher education. The rules are changing, and there is increased pressure on institutions of higher education to evolve, adapt, or desist.

(Swail, 2002, p. 16)

\section{Academic Reform and the Forces for Change}

7 here is little question that colleges and universities are confronting formid1 able forces for change. Critics, budget cuts, and competition have come together to challenge institutional priorities and structures-not to mention faculty, staff, and administrators' roles. Interestingly, the area that will be most directly affected by suggested changes is the one least often discussed-the design and delivery of instruction. In considering recent calls for change and the actions colleges and universities must take to respond to them, it is clear that noc only are fairly fundamental changes needed in the areas of course and curricular design and pedagogy, but that these changes must be accomplished with few resources and with many factors complicating the change process (see Table 2.1). Compounding the problem are increasing demands by accrediting bodies and other external entities that these changes take place within a relatively short timeframe. 


\section{The Role of Accreditation}

While many of the problems being identified are not new-ad hoc curricula, educational deficiencies among graduates, lower success rates for students of color, a disconnect between what institutions say they value and what they reward, and little use of educational research in teaching-it has been only recently that the professional and regional accrediting agencies have moved these problems to the top on their agendas. Recognizing the need for increased institutional accountability, there is concern that if colleges and universities do not deal with these problems, external mandates as seen in the $\mathrm{K}-12$ sector are likely. Those responsible for accreditation have begun to address the quality of teaching and the nature of learning at colleges and universities in the United States. The approach and specific descriptions may differ, but the new standards of each of the major accrediting bodies now call for evidence of student learning, statements of intended outcomes, evidence that data on learning is being collected and used, and that attention is being paid to professional development for faculty and staff.

This shift away from a reliance on input variables (e.g., the number of $\mathrm{Ph}$.Ds on the faculty, the number of books in the library) to output criteria (e.g., stated performance goals in measurable terms and collection and use of data to assess students' ability to reach identified goals), now evident in all accrediting standards, was first observed in the professionally accredited areas such as engineering (Accreditation Board for Engineering and Technology [ABET]) and business and management (Association to Advance Collegiate Schools of Business [AACSB]). An important benefit of this shift is that it allows institutions and programs to determine the specific criteria on which they will be judged rather than having an external group determine the specific structure and content of the curriculum. (For a review of these changes, see www.ou.edu/idp/materials/accrediting.htm.)

In requiring clear and measurable goals for student learning, a cohesive curriculum should be designed to provide students with the opportunity to reach these goals. Courses should include assessment to determine the extent to which these goals are reached. In addition, a professional development program that provides faculty, administrators, and staff with the knowledge and skills required to reach stated goals is essential. These standards require a focus on teaching and learning that does not exist on many campuses. Thus, while this new emphasis would seem to be good news, the problem at most institutions is that faculty and staff may not be adequately prepared for these roles in the new learning paradigm (Tagg, 2003). 
TABLE 2.1

Forces for Change: Impacts on Academic Affairs

Forces for Change

\section{FiscallFinancial}

Decreasing state and federal support

Decreasing foundation assistance

Increasing operating costs

Increasing or decreasing enrollments in the institution or in specific programs

Decreasing enrollments

Increased costs of nonfunded federal mandates

Increased costs of technology

Increased cost of deferred maintenance
Possible Institutional Responses

Restructure academic programs to be cost efficient while improving academic quality

Eliminate duplication of programs and courses Eliminate low-enrollment and low-priority programs

New configurations of academic units (combining departments or schools/colleges)

Limit expensive faculty research to high-priority areas

Place higher priority on faculty and staff activities that support institutional priorities

More efficient scheduling of teaching/classes

Expand the use of technology to reduce instructional cost per student

Restructure budget systems to support instructional priorities

Increase emphasis on fundraising to support academic priorities

Increase collaboration/resource sharing between institutions (i.e., academic programs, libraries, and other service areas)

\section{Teaching and Learning}

Demands for improved quality

Redesign of courses and curricula with intended

Demands for increased accountability

Demands for increased community involvement

Accreditation standards for learning outcome and performance indicators

learning outcome statements and associated data collection and use

Increase emphasis on faculty development

Direct the relationship berween stated intended outcome goals and student assessment

Expand the use of technology to improve instructional effectiveness

Increase application of research on learning, student development, and pedagogy 


\begin{tabular}{ll}
\hline Forces for Change & Possible Institutional Responses \\
\hline & Expand scope of scholarship to support research on \\
new approaches to learning, teaching. \\
course/curriculum design \\
Expand individualization of instruction \\
Expand students' opportunities for internships and \\
professional/job related experiences \\
Increase use of peer teaching and small group \\
interactions
\end{tabular}

\section{Students}

Increasing enrollment

Increasing diversity

Increasing number of under-prepared students

Increasing percentage of adult and part-time students

Increasing numbers taking courses from two or more institutions

Increased number of students taking college-level courses in high school

Increased number of students with work experience
Increase cooperation and integration between student affairs and academic affairs

Increase attention paid to prerequisites and students with advanced study or work experience

Increase in credit and time fexibility Improve use of available student cime Develop systems that facilitate the transferring of credit

Increase use of nontraditional courses, including web-based or distance formats

More flexibility in course requirements and use of exemptions

\section{Faculty}

More diversity, including more women Increase faculty grants to support instruction-related Changing priorities of faculty with more emphasis on non-institutionrelated activities

Continuing growth in part-time positions

Increasing number of retirements activities

Increase attention to interpersonal relations, team building

Increase flexibility in the renure system and the use of part-time tenure positions for designated periods

Increase part-time positions with longer term appointments and improved benefits

Restructure reward systems to relate more directly to the mission and vision of the institution, and to school, college, and academic unit priorities 


\begin{tabular}{ll}
\hline Forces for Change & Possible Institutional Responses \\
\hline Changing faculty roles, more time spent in \\
community with professional development viewed as \\
an integral part of assignment \\
Reduce reliance on lecturing, more contact with \\
students, with small groups, on assessment, and on \\
course and curriculum design \\
Scope of scholarly activities expanded. Greater \\
atrention paid to the quality and significance of schol- \\
arly activities
\end{tabular}

V. Competition and Technology

Increased compecition from the for-profit sector

Increased competition from other institutions

Increased availability of technology

Increase in off-campus programs and learning opportunities

Reduce cost of income-producing programs with associated use of technology

Increase attention paid to the benefits of direct contact with faculty and other students in traditional residential institutions

Increase emphasis on quality of programs and deliverable outcomes

Increase emphasis on skills and knowledge needed for success after graduation

Identify institution's unique strengths and establish priorities accordingly

Increase in use of distance learning and nontraditional delivery options 


\section{The Elements of a Successful Change Process}

The significant kind of organizational change required to implement the various initiatives described in Table 2.1 is not beyond the reach of colleges and universities. However, it will require effort and commitment on the part of administrators, faculty, and staff-and attention to shifting priorities and the change process. Fortunately, the research on change, and on teaching and learning, provides guidelines about prerequisite conditions, steps in the change process, and the characteristics of the campus climate that must be established if change initiatives are to be successful. These include:

- The importance of a clearly articulated institutional mission and vision statement that addresses the needs of students and society and is supported by administrators, faculty, and staff of the institution

- Departmental or divisional priority statements that specifically support the institution's mission and vision

- Students' learning and development at the center of the institution (while the research mission of major universities will remain a priority, it must be balanced with the institution's teaching mission)

- Research on change and leadership, learning and teaching, and knowledge of the institution's culture taken into account in all decision-making

- Leadership for change effectively integrated throughout the institution (see the following section)

- Institutional leaders with a vision for their institution and a clear understanding of their specific roles in the change process

- Administrative and faculty leaders who are knowledgeable and skilled in such areas as institutional change, teaching, learning, leadership, and technology, and clear about their own strengths and weaknesses

- Rewards and recognition for those units and individuals who are successful in meeting the stated institutional priorities

- Decision-making based on continuous monitoring of the quality of learning through the collection and use of assessment data

- Professional development of faculty and staff to support institutional initiatives

- Academic leaders working collaboratively to explore new structures, procedures, and relationships 
- A willingness to rest all previous assumptions

- Commitment to change at all levels of the institution-faculty, administrators, students, and staff ${ }^{1}$

Without attention to these conditions, lasting reform will be a struggle with an all too predictable outcome. Campus leaders must lead the way and take key steps to determine the actions that will lead to a successful and lasting change initiative. Fortunately, on most campuses, talents and resources abound that, if used well, can play important roles in this process.

\section{An Integrated Model of Academic Reform}

As noted, fundamental and long-lasting changes require that 1) campus leaders at all levels of the institution (trustees, president, vice presidents, deans, chairs, directors, and faculty leaders) have both a clear set of common goals and priorities and the knowledge and skills necessary to provide the leadership their roles require, and 2) all units of the institution (academic affairs, student affairs, development, budget, and physical plant) are willing to work together toward these common goals. This is a tall order, to be sure.

\section{Getting Started}

\section{Establishing a Sense of Urgency and Setting Priorities}

While each of the forces for change identified in Table 2.1 may affect all colleges and universities to some degree, it is important to note that the significance will differ from institution to institution. Budget cuts in some states are far more drastic than in others, private institutions have to address different challenges than those in the public sector, the academic backgrounds of students vary considerably across institutions, and deadlines for meeting the new accreditation standards can be quite different from institution to institution and from professional program to professional program.

Because institutions routinely pursue multiple agendas simultaneously, campus leaders must determine which specific forces for change need to be addressed, by whom, and in what priority. Once these decisions are made, it is the further responsibility of this group to assign responsibility and to communicate a sense of urgency throughout the institution. Unless the need to change is clearly understood by faculty and staff, there will be little chance of any initiative being successful. Also keep in mind that the hard work associated with dealing directly with most of these forces will need to be done at the school, college, or department level, or in the support unit where alternative solutions will need to be explored and specific actions will need to be taken. 


\section{Developing an Action Plan}

There are few institutions that will need to start from scratch to address these issues. A significant body of literature exists to assist in the change process. Once problems are identified and priorities are established, the next step that leadership should take is to review the literature on organizational change and leadership as a background for developing an institutional action plan. A list of recommended resources will be found at the end of this chapter. Review of the literature should be followed by a careful analysis of existing campus resources such as academic support offices and faculty expertise that could be used effectively to facilitate and implement the change process. Academic leaders must keep in mind that implementing major reform requires action on their part, but they cannot do it alone, since they may not have either the time or the depth of expertise needed in key areas. Delegating the responsibility for implementation to key offices and focusing on their roles as campus leaders is an important challenge for administrators. The very fact that priorities are established and communicated and that leadership responsibilities are assigned at a high level in the institution also plays a key role in establishing a sense of urgency for initiatives that follow.

\section{The Institutional Change Agency}

Although the first response to the need for advice and guidance may be to turn to national experts, it is important to keep in mind that outside consultants can help an institution develop an action plan, communicate a sense of urgency, and provide specialized assistance in a number of areas, but they are often unavailable for sustained involvement and are far too expensive to rely on for the day-to-day activities that will be required. In addition, consultants are often perceived by faculty and staff as outsiders to institutions, significantly limiting their ability to participate in many of the difficult conversations that will be required. It makes good sense for institutions to establish their own agencies (offices, departments, or units) to provide the coordination, facilitation, and technical assistance that administrators, faculty, and staff will need. It may be tempting to appoint a commitree or task force for such initiatives, but, in fact, change is an ongoing process and establishing a centralized location for work in this area clearly signals that change is here to stay.

A single coordinating agency is suggested for a number of other reasons. First, it cuts down on duplication of effort and competition for scarce resources. Second, it makes it easier for faculty and staff to identify and use the services that are provided, and third, it enhances your outcome by allowing for a combination of related talents and expertise. Although the size of this office 
will be directly related to the size of the institution, there are key services that should be available through this agency.

- Professional development. Offering workshops, leadership seminars, and consultation to faculty, administrators, and staff with a focus on using the research on learning and student development, change, and pedagogy. Programs to focus on include such topics as technology, new forms of instruction, writing learning outcomes, leadership, and assessment.

- Course and curriculum design. Assisting faculty in reviewing existing programs, curricula, and courses, in designing new offerings, and in writing and evaluating outcome statements for all courses and programs.

- Assessment and evaluation. Assisting faculty, administrators, and staff in the design of data collection strategies and in reporting and interpretation of data.

- Facilitation. As experts with process skills and as neutral chairs of key committees and task forces, this role allows institutions to avoid the problems associated with having chairs of these groups also advocate for a particular unit or approach. A neutral approach provides objectivity and expertise in group process, which are important when emotionally charged changes are being explored.

\section{Locating the Center}

Where the unit responsible for such work resides in the organizational structure is an important variable and signals to the campus community the relative importance of the change process and initiatives. Ideally, the unit would be located in the office of the provost or chief academic officer. This location not only recognizes the importance of the work of the agency but can eliminate institutional red tape by reducing competition among service providers. Such affiliation also allows the chief academic officer of the institution to directly establish its priorities and determine its scope of work.

\section{Staffing the Center}

Fortunately, much of the expertise to support change already exists on most campuses in the faculty, instructional, or teaching center; in the office of institutional research, library, or technology center; and within the faculty. What this chapter proposes is that all of these talents can be located in a single unit charged specifically with facilitating and implementing the desired actions. Ideally, this unit has two important characteristics. First, its staff are 
perceived as professional support personnel to the entire institution. Second, new programs and initiatives that are cooperatively developed with faculty or staff from other units of the institution are not placed within this agency or center once they are operational but within their appropriate academic home. This is essential if the unit is to be perceived as an office whose primary goal is to help others to be successful. It also allows the staff of the unit to move on to other priorities when a project is completed. This office becomes, in effect, the campus "strike force" for organizational change. If additional support funds for such an office are limited, and they often are, it may make sense to explore a combination of a full-time leadership and clerical staff with part-time faculty and technical appointments in specialized areas.

\section{Expanding the Role of Faculty, Instructional, or Teaching Centers}

Most campuses today include a center or office for teaching, academic excellence, or instruction. As one option, institutions can expand the role of this office that exists on many campuses. This approach has a number of advantages.

- The unit most likely is already located in the academic affairs office.

- The unit is already perceived as a source of support by faculty and staff.

- The unit most likely already includes a staff of professionals knowledgeable about research on teaching, learning, assessment, and evaluation, who have experience in helping faculty write learning outcomes and in offering workshops and seminars, and on some campuses, expertise with use of technology. In addition, most units include staff with the process skills that are ideal for facilitating working groups.

- These units may also have support and production staff to assist with such activities as editing, graphic design, and technology.

While few units will have all of the needed competencies or the number of staff members that may be required, these offices, by their very nature, are ideally staffed and located to serve in the role of change agents. While some of the required staff may currently be housed part-time in the technical support offices, the library, or on the faculty, a central unit has the potential to significantly reduce competition between support offices by facilitating an open discussion before major, and often quite expensive, instructional options are identified. The individual chosen to lead such a unit must have high-level process skills, a focus on organizational change, and most importantly, not be an advocate of any single solution. This person must also be respected both by faculty and institutional leaders. 


\section{Staff Development}

Many of the skills and much of the knowledge that will be required for an institutional change agency can already be found on most campuses; however, some important skills may need to be developed or refreshed. As a result, early attention must be paid to staff development. This should not be surprising, since the full range of potential initiatives described in Table 2.1 will be relatively new to most institutions. The need for planned staff training becomes even more important when key activities need to be undertaken simultaneously across an institution, requiring the use of other faculty and staff on a part-time basis-individuals who will need to be carefully selected and then prepared for their specific assignment.

Table 2.2 is a checklist that can be used to help determine any gaps in essential knowledge and skills on your campus, the first step in designing a professional development program for agency staff. Keep in mind that no one individual can be expected to have all the needed knowledge and specialized skills identified, and that while some of the knowledge and skills are appropriate for all staff members, others, requiring specialization, must exist but not in every staff member. Much of the knowledge required is available in the references identified in the Resource section at the end of this chapter, but some specific skill development may be needed for some staff. Workshops and seminars addressing many of these skill areas are available through the Professional and Organizational Development Network in Higher Education (POD) and the American Association for Higher Education (AAHE), and via a number of entities that offer workshops on leadership and change. In some cases, it may be most cost effective to offer specific topic workshops for staff and faculty on your own campus.

TABLE 2.2

A Checklist for Change Agency Staff

\begin{tabular}{lcc}
\hline & \multicolumn{3}{c}{ Level of Proficiency } \\
Area & Ho Not \\
\hline
\end{tabular}

I. Knowledge

An understanding of the literature and research on:

- Organizational theory as it applies to colleges and universitics

- Mission and vision development

- Leadership (motivation and change)

- Leadership (management and governing)

- Teaching, learning, and teaching techniques 


\begin{tabular}{lcccc}
\hline & \multicolumn{3}{c}{ Level of Proficiency } \\
Area & High & Medium & Low & Have \\
\hline - Technology & $\square$ & $\square$ & $\square$ & $\square$ \\
- Course and curriculum design & $\square$ & $\square$ & $\square$ & $\square$ \\
- Evaluation and assessment & $\square$ & $\square$ & $\square$ & $\square$ \\
- Group processes & $\square$ & $\square$ & $\square$ & $\square$ \\
- Advising & $\square$ & $\square$ & $\square$ & $\square$ \\
- Grant writing & $\square$ & $\square$ & $\square$ & $\square$ \\
\hline II. Skills & & & & \\
The ability to effectively: & & & & \\
- Select, manage, and implement priority projects & $\square$ & $\square$ & $\square$ & $\square$ \\
- Participate as a member of a team & $\square$ & $\square$ & $\square$ & $\square$ \\
- Lead groups & $\square$ & $\square$ & $\square$ & $\square$ \\
- Select members of a team & $\square$ & $\square$ & $\square$ & $\square$ \\
- Assist faculty in designing courses/curricula & $\square$ & $\square$ & $\square$ & $\square$ \\
- Assist faculty in writing learning outcomes & $\square$ & $\square$ & $\square$ & $\square$ \\
- Design, administer, and interpret surveys, tests, & & & & \\
and other data collection instruments & $\square$ & $\square$ & $\square$ & $\square$ \\
- Assist faculty in selecting appropriate & & & & \\
instructional approaches and technologies & $\square$ & $\square$ & $\square$ & $\square$ \\
- Assist faculty in the design of instructional & & & & \\
- materials, both media and print based & $\square$ & $\square$ & $\square$ & $\square$ \\
- Edit materials & $\square$ & $\square$ & $\square$ & $\square$ \\
- Assist faculty and administrators in grant writing & $\square$ & $\square$ & $\square$ & $\square$ \\
\hline & $\square$ & $\square$ & $\square$ & $\square$ \\
\hline
\end{tabular}

\section{IN SUMmaRY}

Colleges and universities are increasingly being confronted by forces that call for major changes in their structures, their priorities, and the roles of faculty, students, and staff. At the same time, more students with greater needs must be served with fewer resources. While those in top leadership positions have the responsibility for establishing and communicating a sense of mission and vision and for providing direction and priorities, they certainly do not have the time and may lack the professional expertise needed for facilitating and directing the many campus-wide initiatives that will be required. For this reason, a centrally located unit charged with facilitating and supporting the various interrelated change activities is proposed. 
Without such a cost-effective office, major institutional reform will remain a troublesome challenge with all the related accreditation problems. The problems every institution will face in the next decade are both urgent and complex, and we cannot delay any longer in addressing them. We have the knowledge and skills to do what needs to be done. Whether each campus has the willingness, the leadership, and the dedication to do so is another matter.

\section{ENDNOTE}

'Modified from Diamond, R. M. (2002). Field guide to academic leadership. San Francisco, CA: Jossey-Bass. Pages xxx-xxxi.

\section{RESOURCES}

\section{The Academic Change Library}

Basic Resources: There are two references that are recommended for reading by decision makers as they begin to develop an action plan for their institution and for those in leadership roles at the school, college, department, and unit levels as well as those in the institutional change agency.

Kotter, J. (1996). Leading change. Boston, MA: Harvard Business School Press.

This easy-to-read, practical volume describes an excellent model for change that can be easily adapted to higher education. Academic leaders who have used it have found it to be extremely helpful.

Diamond, R. M. (Ed.). (2002). Field guide to academic leadership. San Francisco, CA: Jossey-Bass

This book. from the National Academy for Academic Leadership, is designed to provide basic information on a range of key topics. National leaders address topics and issues of interest to academic leaders at all levels: administrative issues and leadership; institutional culture; mission and vision statements; the latest research on learning, student development, and teaching; course and curriculum design and evaluation; faculty roles and rewards; technology; advising; diversity; collaboration between academic affairs and seudent affairs; and supportive budget structures. Also included are chapters addressing specific leadership issues by position, a number of checklists for change agents, and annotated bibliographies of references for additional information. 
Other key resources for anyone involved in rethinking educational processes.

Research on Teaching and Learning

Gardiner, L. F. (1996). Redesigning higher education: Producing dramatic gains in student learning (ASHE-ERIC Higher Education Report, 23[7]). San Francisco, CA: Jossey-Bass.

\section{Assessment}

Palomba, C. A., \& Banta, T. W. (1999). Assessment essentials: Planning, implementing, and improving assessment in higher education. San Francisco, CA: Jossey-Bass.

\section{Teaching}

McKeachie, W. J., \& Associates. (2002). Teaching tips: Strategies, research, and theory for college and university teachers (11 th ed.). Boston, MA: Houghton Mifflin.

Course and Curriculum Design-The Process

Diamond, R.M. (1997). Designing $\delta$ assessing courses of curricula: A practical guide (Rev. ed.). San Francisco, CA: Jossey-Bass

\section{Promotion, Tenure, Scholarship, and Faculty Rewards}

See the wide range of publications on these topics from Anker Publishing (www.ankerpub.com), including materials and guide books on serving on promotion and tenure committees, preparing institutional and department guidelines, preparing personal professional portfolios, and for faculty preparing for review.

\section{REFERENCES}

Swail, W. S. (2002, July/August). Higher education and the new demographics: Questions for policy. Change, 34(4), 15-23.

Tagg, J. (2003). The learning paradigm college. Bolton, MA: Anker. 